\title{
Unusual Digital Patterns In EPS: Evidence On The Association Between Earnings Management And Company Characteristics
}

\author{
Charles E. Jordan, (Email: charles.jordan@usm.edu),University of Southern Mississippi
}

Stanley J. Clark, (Email: stanley.clark@usm.edu), University of Southern Mississippi

Mary Anderson, (Email: mary.anderson@usm.edu), University of Southern Mississippi

\begin{abstract}
Prior studies (Thomas, 1989; Das and Zhang, 2003) provide evidence of earnings manipulation to achieve cognitive reference points in EPS. The current study extends this line of research by examining the relation between unusual digital patterns in the right EPS position and specific firm characteristics. Results suggest that the propensity to manage earnings to effect desired EPS results is particularly associated with company size and to a lesser degree with operating performance and the level of debt leverage employed.
\end{abstract}

\section{INTRODUCTION}

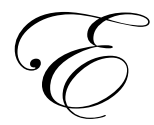

arnings management represents deliberate actions taken within the financial reporting process to create desired outcomes. As Jackson and Pitman (2001) note, earnings management is typically perpetrated to create personal gain. Its presence is widely documented in the accounting literature as managers seek to manipulate income to meet analysts' forecasts (Degeorge et al., 1999; Payne and Robb, 2000), to increase their own wealth via bonus agreements tied to income (Healy, 1985, Guidry et al., 1999), or to enhance stock-price performance and the ensuing benefits accruing to them from share-based compensation plans (Brown and Higgins, 2001). Generally, earnings management is orchestrated through the use of accruals and estimates inherent in the financial reporting process.

Determining the existence of earnings management represents a difficult undertaking because it can be proven definitively only by knowing the mindset of management. Instead, studies examining earnings management normally rely on indirect, anecdotal evidence and the collective actions of a large number of companies to ascertain its presence. These studies often consider patterns in reported income numbers as evidence of earnings manipulation. For example, Thomas (1989) shows that zeros and fives appear as the right digit in EPS (e.g., 5 in the EPS number \$1.15) more frequently than expected for firms with positive earnings. He speculates that these large deviations may be the result of substantial rounding bias in EPS numbers occurring because of the "\$1.99 pricing phenomenon." More specifically, a price of $\$ 2.00$ is perceived to be substantially larger than a price of $\$ 1.99$. Thus, when EPS is just below a reference point (e.g., either a five or a zero in the right digit), management manipulates earnings to achieve this EPS breakpoint.

Other studies show that the propensity to manage earnings may be related to company characteristics, such as firm size (Manzon, 1992), level of debt leverage (Sweeney, 1994), and operating performance (Yoon and Miller, 2002). The current study extends the body of research examining the manipulation of the right EPS digit by investigating whether the likelihood of such manipulation is related to the company characteristics noted above (i.e., firm size, debt leverage, and operating performance). Although the results do not necessarily follow the digital EPS patterns found in prior research (e.g., Thomas, 1989), they suggest the presence of earnings management in that the 
distributions of the right EPS digit appear to be related to the company characteristics examined.

\section{LITERATURE REVIEW}

In the last several years, a subset of earnings management research has developed that concentrates on the manipulation of either earnings or EPS to achieve cognitive reference points. For example, studies demonstrate that income is managed to meet analysts' earnings forecasts (Degeorge et al., 1999; Payne and Robb, 2000; Jordan and Clark, 2003). The benefit to companies from meeting these earnings reference points is that firms attaining or exceeding earnings expectations enjoy continued growth in their share price.

Research also examines the rounding of earnings in relation to the "\$1.99 pricing phenomenon," as discussed earlier. Carslaw (1988) speculates that the second-from-the-left digit in income numbers will follow an abnormal distribution with an unusually low occurrence of high digits as managers manipulate earnings to round up this second digit to a reference point in the first digit. Carslaw (1988) tests his theory on the earnings figures for a sample of New Zealand firms and concludes that it represents an accurate description of management's behavior. In particular, there exists a much higher than expected frequency of zeros and lower than expected frequency of nines in the second earnings digit.

Thomas (1989) replicates Carslaw's (1988) study using the earnings figures for U.S. firms and observes similar results (i.e., fewer nines and more zeros than expected in the second digit) for firms with positive earnings. For companies with negative earnings, however, Thomas (1989) discovers just the opposite result (i.e., more nines and fewer zeros than expected in the second digit). Unlike firms with profits, companies with losses appear to avoid rounding to larger numbers. Van Caneghem (2002) replicates the Carslaw (1988) and Thomas (1989) studies using a sample of U.K. companies and finds similar results. Finally, Van Caneghem (2004) examines the impact of audit quality on this rounding-up behavior and concludes that no difference exists in the propensity of Big Five versus non-Big Five auditors to constrain this earnings rounding.

Das and Zhang (2003) investigate the rounding of EPS to meet reference points. They note that rounding up can add only one more cent to EPS but even this small amount may produce significant valuation results. Das and Zhang (2003) speculate that the rounding of EPS is effected through the use of small working capital accruals to adjust earnings. For example, assume a company's non-rounded EPS is $\$ .1948$ (i.e., net earnings of $\$ 2,135,760$ divided by $10,963,860$ shares). Normal rounding policy would round this down to a reported EPS of $\$ .19$. With additional income of only $\$ 2,200$, non-rounded EPS becomes $\$ .1950$ and rounded EPS reported in the financial statements would be $\$ .20$. Thus, a minor adjustment to earnings (i.e., the numerator in EPS) that would fly under the radar of virtually any materiality threshold can easily result in a one-cent rounding of EPS. Notice also that this seemingly unimportant one-cent increase in EPS raises it by 5.26\%, a not-so-insignificant jump.

Das and Zhang (2003) find compelling evidence that managers indeed manipulate earnings so they can round up and report one more cent of EPS. More specifically, their results indicate managers manipulate earnings through short-range, discretionary accruals so that their firms can attain behavioral thresholds (i.e., meet analysts' forecasts, report profits, or sustain recent performance).

Thomas (1989) examines the patterns in reported EPS numbers for a large sample of U.S. companies. For positive earnings firms, he finds that zeros and fives appear as the right EPS digit more frequently than expected. As plausible explanations for these unusually high frequencies of zeros and fives, Thomas (1989) offers the "\$1.99 pricing phenomenon" as well as the notion that lending and compensation contracts are often denominated in round earnings numbers. Thus, management may adjust earnings numbers so EPS can meet these round figures.

Another line of earnings management research investigates the characteristics of companies that are more likely to engage in earnings manipulation. For example, Watts and Zimmerman (1986) note that leverage may be viewed as a proxy for financial risk. Therefore, companies that are more heavily debt leveraged may be more prone to manage earnings in order to report positive and stable earnings to compensate investors for the greater risk associated with higher debt levels. Numerous empirical studies (e.g., Glaum et al., 2004; Visvanathan, 1998; 
Porcano, 1997; Aharony et al., 1993) support this theory by providing evidence that earnings management is more prevalent among highly leveraged firms than it is with companies possessing low debt levels.

Firm size has also been linked with the propensity to manage earnings, although mixed results exist concerning exactly how entity size relates to this behavior. For example, Watts and Zimmerman (1986) suggest that managers of larger firms may be likely to manipulate earnings downward to avoid high profits and the political scrutiny that accompanies it. Glaum et al. (2004) hypothesize that large international companies may have more opportunity to manage earnings than small national firms simply because the former group typically must adhere to more complex accounting standards involving subjectivity. However, the empirical results from Glaum et al. (2004) show that smaller firms manage earnings more intensively than larger ones. They surmise that smaller firms may find it more difficult than larger ones to raise equity capital and, thus, capital-market-oriented earnings management may be more important for smaller companies. Aharony et al. (1993) also provide evidence that earnings management is more pronounced with smaller companies than with larger ones.

The level of operating performance is also tied to the likelihood of managing earnings. For example, Yoon and Miller (2002) conclude that, when operating performance is poor, firms tend to choose income-increasing strategies. Similarly, Burgstahler and Dichev (1997) find that managers manipulate earnings to avoid reporting losses and decreases in earnings. Peek's (2004) results indicate that, when current earnings are low relative to the preceding year and the depressed earnings are transitory, firms report unexpectedly large discretionary provisions (expenses), which is commonly referred to as the "big bath."

The purpose of the current research is to extend the work of Thomas (1989), which examines the right EPS digit for unusual patterns, by incorporating the findings from the studies investigating the association between firm characteristics and the propensity to manage earnings. More specifically, is the likelihood of managing earnings to report "round" or specific EPS numbers related to firm size, debt leverage, or operating performance?

\section{METHODOLOGY}

To ascertain if there is a link between the propensity to report specific EPS numbers and firm size, debt leverage, or operating performance, 2006 year-end financial statement data are collected on 1002 randomly selected, publicly traded U.S. companies. Data are collected from the LexisNexis Business database. Thomas (1989) concludes that the propensity to round earnings to reference points exhibits little industry differences. Thus, for the current study, data are obtained on companies from virtually all industry types. This allows the results of the study to have wider application than if only specific industries are examined.

As Das and Zhang (2003) point out, earnings management to effect the rounding of EPS numbers can typically add only one cent to EPS. Thus, the digit of interest in the current study is the right digit in basic EPS. To reduce the level of noise in EPS, only companies not reporting discontinued operations or extraordinary items in income are included in the sample. That is, only one basic EPS number is reported in 2006 for each company in the sample. To determine if companies manipulate earnings to round the right EPS digit to specific reference points, a crucial assumption must be made concerning the distribution of digits that would occur in this earnings position in the absence of earnings management.

Benford's (1938) law states that digits in naturally occurring numbers do not follow random patterns, and his research provides hypothesized proportions for each of the 10 digits in the first four positions within a number. For example, the expected proportion that a one would appear as the first digit is $30.1 \%$ while the expected proportion of a two as the first digit is $17.6 \%$ and so forth. Benford (1938) finds that his expected digital frequencies hold true in a wide number of applications (e.g., the areas of rivers, numbers in a Reader's Digest issue, etc.). Pinkham (1961) shows that Benford's law is scale invariant. That is, if a group of numbers follows Benford's law, the numbers will continue to follow Benford's expected digital frequencies if every number in the group is multiplied by a non-zero constant (e.g., 3.5 or .623). More recent studies (e.g., Carslaw, 1988; Niskanen and Keloharju, 2000) note that the reported income numbers for firms should follow Benford's expected digital frequencies as well. 
When analyzing the EPS numbers for his sample of firms, though, Thomas (1989) discovers that the EPS digits follow frequencies markedly different from those postulated by Benford (1938). Thomas (1989) concludes that Benford's frequencies are inappropriate for performing digital analysis of EPS numbers but offers no explanation of why EPS digits should not follow Benford's widely accepted digital frequencies. The likely reason is because EPS numbers are not the result of multiplying all income numbers for a group of firms by a constant but rather result from dividing the earnings for each firm by that company's unique number of shares. Thus, Pinkham's (1961) theory of scale invariance does not apply to EPS, and as a consequence EPS numbers would not be expected to conform to Benford's hypothesized digital frequencies. Das and Zhang (2003) note that, in the absence of earnings management, the cross-sectional distribution of digits in EPS to the right of the decimal point would be expected to be relatively smooth. More specifically, to the right of the decimal point in EPS, each of the digits zero to nine should have an equal (i.e., 10\%) chance of occurring.

For the reasons just noted, in the current study the hypothesized frequency of digits in the right EPS position is equal or proportional (i.e., each digit from zero to nine should occur in this position approximately $10 \%$ of the time). If the observed frequencies of the right EPS digits for the sample companies adhere to these expected frequencies, evidence exists suggesting that earnings are not being managed to reach desired reference points in EPS. If, however, observed frequencies differ from these expected frequencies, strong anecdotal evidence exists indicating that earnings are managed to create desired EPS results.

To determine if company characteristics impact the propensity to manage earnings to effect desired EPS results, the group of 1002 firms is split into subgroups based on particular financial characteristics. To begin the analysis, the sample is divided into two subgroups, one containing positive earnings firms and the other containing negative earnings firms. If income is manipulated to achieve specific EPS numbers, it is presumed that positive earnings firms and negative earnings firms would seek different EPS reference points. In line with the "\$1.99 pricing phenomenon," positive earnings firms would desire a larger EPS figure (i.e., an EPS of $\$ .10$ would be considered much more desirable than an EPS figure of \$.09). Negative earnings firms would manage earnings to achieve the opposite effect (i.e., an EPS of \$-.09 would be preferable to an EPS of \$-.10). The digital frequencies for the right EPS position observed for each subgroup are compared to the hypothesized (i.e., proportional) frequencies using one-sample proportions test to determine if unusual digital patterns exist for either subgroup.

Burgstahler and Dichev (1997) conclude that a primary reason companies manage earnings is to avoid reporting losses. Thus, for the companies already reporting losses, there is much less need to manipulate earnings relative to firms reporting profits. Simply put, negative earnings firms have missed their earnings mark so substantially that little benefit may be obtained through earnings management geared toward reaching certain EPS reference points. Rather than try to reach specific EPS reference points, negative earnings firms may take "big baths" in the current year to clear the decks for future periods. Significant research (e.g., Peek, 2004; Yoon and Miller, 2002) indicates the presence of this "big bath" earnings management for firms with depressed earnings. Because negative earnings firms have less incentive to manage earnings to report EPS amounts at particular cognitive reference points and more incentive to take big hits to income without regard to their effect on EPS, the remainder of the analyses in the current study concentrates on the subgroup of companies reporting positive earnings. This is consistent with both Carslaw (1988) and Van Caneghem (2002).

Of the 1002 firms in the sample, 749 reported positive earnings in 2006. This group of positive earnings firms is further divided into subgroups based on the company characteristics that have been linked to the propensity to manage earnings (i.e., firm size, debt leverage, and operating performance). For example, the group of positive earnings firms is split into two subgroups according to company size as measured by total assets. The observed frequencies of the right EPS digit for each subgroup are then compared to the expected (i.e., proportional) frequencies to determine if unusual digital patterns exist for either subgroup. The observed frequencies of the subgroups are compared to the hypothesized frequencies rather than to each other because any differences in observed frequencies between the two subgroups would be rather meaningless with little interpretive value. For example, if the two subgroups have different observed frequencies in reporting fives in the right EPS digit, there would be no way to ascertain which group, if either, manipulated earnings. An analysis similar to the one just described for company size is repeated for the group of positive earnings firms subdivided by leverage and also by operating performance. 


\section{RESULTS}

For the full sample of firms segregated into two subgroups based on positive versus negative earnings, Table 1 presents the observed counts and frequency distributions of each digit (i.e., zero through nine) occurring in the right EPS position. As an example, for the negative earnings firms, the digit zero occurs in the right EPS position for 26 firms, which represents $10.3 \%$ of the total 253 companies with negative earnings. As discussed previously, the expected frequency is proportional at $10 \%$. A one-sample proportions test comparing the observed frequency of $10.3 \%$ with the expected frequency of $10 \%$ results in a Z-value of .147 with a $p$-level of .883 . The counts and frequencies for the other nine possible digits for the negative earnings firms as well as the ten possible digits for the positive earnings firms would be analyzed in a similar fashion. Using a cutoff (i.e., alpha) level of .05, the $p$-levels in Table 1 show that the observed frequency for no digit, for either subgroup, differs significantly from its expected frequency of $10 \%$.

Table 1

EPS Digital Frequencies for Negative and Positive Earnings Firms

\begin{tabular}{|c|c|c|c|c|c|c|c|c|c|c|}
\hline \multirow[b]{2}{*}{$\begin{array}{l}\text { Negative Earnings } \\
\text { Firms }(n=253) \text { : }\end{array}$} & \multicolumn{10}{|c|}{ Right EPS Digit } \\
\hline & 1 & 2 & 3 & 4 & 5 & 6 & 7 & 8 & 9 & $\mathbf{0}$ \\
\hline Observed count (n) & 27 & 32 & 23 & 21 & 22 & 29 & 25 & 30 & 18 & 26 \\
\hline Observed frequency $(\%)$ & 10.7 & 12.6 & 9.1 & 8.3 & 8.7 & 11.5 & 9.9 & 11.9 & 7.1 & 10.3 \\
\hline Expected frequency $(\%)$ & 10.0 & 10.0 & 10.0 & 10.0 & 10.0 & 10.0 & 10.0 & 10.0 & 10.0 & 10.0 \\
\hline $\mathrm{Z}$ value & .356 & 1.404 & -.482 & -.901 & -.692 & .775 & -.063 & .985 & -1.53 & .147 \\
\hline$P$ level & .722 & .160 & .631 & .368 & .490 & .438 & .950 & .325 & .126 & .883 \\
\hline
\end{tabular}

\section{Positive Earnings \\ Firms (n=749):}

$\begin{array}{lrrrrrrrrrr}\text { Observed count (n) } & 72 & 61 & 83 & 65 & 72 & 89 & 70 & 84 & 78 & 75 \\ \text { Observed frequency (\%) } & 9.6 & 8.1 & 11.1 & 8.7 & 9.6 & 11.9 & 9.3 & 11.2 & 10.4 & 10.0 \\ \text { Expected frequency (\%) } & 10.0 & 10.0 & 10.0 & 10.0 & 10.0 & 10.0 & 10.0 & 10.0 & 10.0 & 10.0 \\ \text { Z value } & -.353 & -1.693 & .987 & -1.206 & -.353 & 1.717 & -.597 & 1.108 & .378 & .012 \\ P \text { level } & .724 & .090 & .724 & .228 & .724 & .086 & .551 & .268 & .706 & .990\end{array}$

Note: $\mathrm{Z}$ values and $P$ levels are for a one-sample proportions test comparing the observed frequency of a digit to the expected frequency of $10 \%$.

The results in Table 1 indicate no unusual patterns in the right EPS digit, which stands in stark contrast to Thomas' (1989) findings. His results show that, for positive earnings firms, the digits zero and five occur much more frequently than expected in the right EPS position while the digit nine appears much less often than expected. His findings lead him to conclude that particular evidence of rounding EPS (i.e., earnings manipulation) exists for positive earnings firms as companies tend to manage earnings to allow rounding to cognitive reference points in EPS (i.e., EPS with five or zero in the right position).

Table 1 indicates earnings management to effect specific EPS numbers occurs for neither the subgroup of positive earnings firms nor the subgroup of negative earnings firms in the current study. Two possible explanations exist for the different findings in the Thomas (1989) study and the current one. First, Thomas developed his study using 1986 data, while the current study uses 2006 data. It is entirely possible that less earnings management occurs today relative to two decades ago. Recent times have seen a heightened awareness of management misdeeds as financial statement shenanigans at major companies (e.g., Enron, WorldCom, Tyco, Healthsouth, etc.) have cost 
some investors their life savings. The Sarbanes-Oxley Act created stiffer penalties for fraudulent reporting by managers and has made external auditors more independent of their clients and, thus, better able to question and thwart attempts by management to manipulate earnings. Simply put, the greater political and public scrutiny of corporate America today may have resulted in a significant reduction in the manipulation of earnings to achieve specific reference points in EPS.

Second, Thomas (1989) does not compare the observed frequencies for the right EPS digit to expected frequencies that are proportional (i.e., 10\%). Instead, he calculates the expected frequency of an EPS number as the mean of the observed proportions for adjacent EPS numbers. For example, the expected proportion of EPS $=\$ .10$ is the mean of the observed proportions for EPS $=\$ .09$ and EPS $=\$ .11$. He states that his expectations model "assumes that the underlying distribution of EPS numbers under the null hypothesis be smooth (Thomas, 1989, p. 784)." However, his assumption is that the distribution is smooth only over a two-cent range. Thus, the different expectations models used in the two studies could explain their diverging conclusions. For reasons discussed earlier, though, it is believed that a proportional expectations model across all ten digits is appropriate for the current study.

The fact that neither the negative nor positive earnings firms demonstrate unusual patterns in the right EPS digit does not mean that companies do not manage earnings to effect EPS amounts at specific reference points. It does, however, imply that any propensity to do so is unrelated to this one characteristic (i.e., positive earnings versus negative earnings).

The next characteristic examined is entity size. The group of 749 firms with positive earnings is divided into two subgroups based on total assets as the measure of firm size. The median total assets for the group of positive earnings firms is $\$ 736$ million. The 375 companies with total assets above this amount make up the subgroup of large companies, while the 374 firms with total assets below $\$ 736$ million comprise the subgroup of small firms. Table 2 presents the counts and frequencies of the digits in the right EPS position for these two subgroups. The observed frequencies are compared to the expected frequencies (i.e., 10\% for each digit) using onesample proportions test to determine if unusual digital patterns exist in the right EPS position.

Table 2

EPS Digital Frequencies for Large and Small Firms

\begin{tabular}{|c|c|c|c|c|c|c|c|c|c|c|}
\hline & \multicolumn{10}{|c|}{ Right EPS Digit } \\
\hline & 1 & 2 & 3 & 4 & 5 & 6 & 7 & 8 & 9 & 0 \\
\hline \multicolumn{11}{|l|}{ Large Firms $(n=375)$ : } \\
\hline Observed count (n) & 24 & 32 & 46 & 35 & 39 & 50 & 37 & 41 & 31 & 40 \\
\hline Observed frequency $(\%)$ & 6.4 & 8.5 & 12.3 & 9.3 & 10.4 & 13.3 & 9.9 & 10.9 & 8.3 & 10.7 \\
\hline Expected frequency (\%) & 10.0 & 10.0 & 10.0 & 10.0 & 10.0 & 10.0 & 10.0 & 10.0 & 10.0 & 10.0 \\
\hline$Z$ value & -2.324 & -.947 & 1.463 & -.430 & .258 & 2.152 & -.086 & .602 & -1.119 & .430 \\
\hline$P$ level & .020 & .344 & .143 & .667 & .796 & .031 & .931 & .547 & .263 & .667 \\
\hline
\end{tabular}

\section{Small Firms (n=374):}

\begin{tabular}{|c|c|c|c|c|c|c|c|c|c|c|}
\hline Observed count (n) & 41 & 37 & 36 & 35 & 36 & 26 & 36 & 32 & 45 & 51 \\
\hline Observed frequency (\%) & 10.9 & 9.9 & 9.6 & 9.3 & 9.6 & 6.9 & 9.6 & 8.5 & 12.0 & 13.6 \\
\hline Expected frequency (\%) & 10.0 & 10.0 & 10.0 & 10.0 & 10.0 & 10.0 & 10.0 & 10.0 & 10.0 & 10.0 \\
\hline $\mathrm{Z}$ value & .602 & -.086 & -.258 & -.430 & -.258 & -1.979 & -.258 & -.947 & 1.291 & 2.324 \\
\hline$P$ level & .547 & .931 & .796 & .667 & .796 & .048 & .796 & .344 & .193 & .020 \\
\hline
\end{tabular}

Note: $\mathrm{Z}$ values and $P$ levels are for a one-sample proportions test comparing the observed frequency of a digit to the expected frequency of $10 \%$. 
For the subgroups segregated by firm size, deviations exist between the observed and expected frequencies of digits. Using a .05 cutoff level for statistical significance, Table 2 reveals that the subgroup of large firms has a much lower than expected frequency of ones in the right EPS position (i.e., 6.4\%) and a much higher than expected frequency of sixes (i.e., 13.3\%). The statistical significance of these two deviations suggests that they do not occur due to random chance but are orchestrated somehow. Exactly why these two particular digits exhibit unusual frequencies is unknown, but the general pattern is intuitive. In particular, a one appears in the right position less often than expected. The digit one is the smallest non-zero digit and companies likely prefer not to have this as the right EPS digit, especially if the EPS amount overall is relatively low (e.g., an EPS of \$.02 is much larger and more desirable relative to an EPS of \$.01). The higher than expected frequency of sixes could be occurring because management seeks to get the right EPS digit into the upper half of the digital range. For example, in the range of EPS from $\$ .01$ to $\$ .10, \$ .05$ represents the midpoint. An EPS of \$.06 puts EPS "over the hump" and into the upper half of the range. Overall, these results suggest that large companies may be managing earnings to avoid a low reference point of one in the right EPS position yet seeking out a more desirable reference point of six.

For the subgroup of small firms, a different set of unusual digital patterns emerges. There are more zeros than expected (i.e., 13.6\%) and fewer sixes than expected (i.e., 6.9\%) in the right EPS position. The larger proportion of zeros corroborates at least part of Thomas' (1989) results; it suggests that managers of smaller firms may be manipulating earnings to reach a cognitive reference point in EPS divisible by 10 cents. That is, an EPS of $\$ .20$ would be considered much more desirable than an EPS of $\$ .19$. This finding is very much in line with the "\$1.99 pricing phenomenon." The lower than expected proportion of sixes is a bit more perplexing but demonstrates a clear difference between large and small firms (i.e., large firms have more sixes than expected in the right EPS position while small firms have fewer sixes than anticipated).

The group of positive earnings firms is next segregated into two subgroups based on the level of debt leverage. Leverage is measured as the percentage of a firm's debt to total assets; the median debt ratio for the 749 positive earnings companies is $51.69 \%$. The 375 firms with debt ratios above this median comprise the subgroup of high-leverage companies, while those with debt ratios below 51.69\% make up the low-leverage subgroup. Table 3 shows the observed digital counts and frequencies in the right EPS position for these two subgroups.

Table 3

EPS Digital Frequencies for High and Low Leverage Firms

\begin{tabular}{|c|c|c|c|c|c|c|c|c|c|c|}
\hline \multirow[b]{2}{*}{$\begin{array}{l}\text { High Leverage } \\
\text { Firms }(n=375) \text { : }\end{array}$} & \multicolumn{10}{|c|}{ Right EPS Digit } \\
\hline & 1 & 2 & 3 & 4 & 5 & 6 & 7 & 8 & 9 & $\mathbf{0}$ \\
\hline $\begin{array}{l}\text { Observed count }(\mathrm{n}) \\
\text { Observed frequency }(\%) \\
\text { Expected frequency }(\%) \\
\mathrm{Z} \text { value } \\
P \text { level }\end{array}$ & $\begin{array}{r}40 \\
10.7 \\
10.0 \\
.430 \\
.667\end{array}$ & $\begin{array}{r}33 \\
8.8 \\
10.0 \\
-.775 \\
.439\end{array}$ & $\begin{array}{r}43 \\
11.5 \\
10.0 \\
.947 \\
.344\end{array}$ & $\begin{array}{r}34 \\
9.1 \\
10.0 \\
-.602 \\
.547\end{array}$ & $\begin{array}{r}36 \\
9.6 \\
10.0 \\
-.258 \\
.796\end{array}$ & $\begin{array}{r}45 \\
12.0 \\
10.0 \\
1.291 \\
.197\end{array}$ & $\begin{array}{r}30 \\
8.0 \\
10.0 \\
-1.291 \\
.197\end{array}$ & $\begin{array}{r}34 \\
9.1 \\
10.0 \\
-.602 \\
.547\end{array}$ & $\begin{array}{r}43 \\
11.5 \\
10.0 \\
.947 \\
.344\end{array}$ & $\begin{array}{r}37 \\
9.9 \\
10.0 \\
-.086 \\
.931\end{array}$ \\
\hline $\begin{array}{l}\text { Low Leverage } \\
\text { Firms }(n=374) \text { : }\end{array}$ & & & & & & & & & & \\
\hline $\begin{array}{l}\text { Observed count }(\mathrm{n}) \\
\text { Observed frequency }(\%) \\
\text { Expected frequency }(\%) \\
Z \text { value } \\
P \text { level }\end{array}$ & $\begin{array}{r}32 \\
8.6 \\
10.0 \\
-.931 \\
.352\end{array}$ & $\begin{array}{r}28 \\
7.5 \\
10.0 \\
-1.620 \\
.105\end{array}$ & $\begin{array}{r}40 \\
10.7 \\
10.0 \\
.448 \\
.654\end{array}$ & $\begin{array}{r}31 \\
8.3 \\
10.0 \\
-1.103 \\
.270\end{array}$ & $\begin{array}{r}36 \\
9.6 \\
10.0 \\
-.241 \\
.809\end{array}$ & $\begin{array}{r}44 \\
11.8 \\
10.0 \\
1.138 \\
.255\end{array}$ & $\begin{array}{r}40 \\
10.7 \\
10.0 \\
.448 \\
.654\end{array}$ & $\begin{array}{r}50 \\
13.4 \\
10.0 \\
2.172 \\
.030\end{array}$ & $\begin{array}{r}35 \\
9.4 \\
10.0 \\
-.414 \\
.679\end{array}$ & $\begin{array}{r}38 \\
10.2 \\
10.0 \\
.103 \\
.918\end{array}$ \\
\hline
\end{tabular}

Note: $\mathrm{Z}$ values and $P$ levels are for a one-sample proportions test comparing the observed frequency of a digit to the expected frequency of $10 \%$. 
For the subgroup of high-leverage firms, no unusual digital patterns exist as no observed frequency differs from its expected frequency at an alpha level of .05 or lower. For the low-leverage subgroup, only one digit (i.e., eight) exhibits an unusual pattern with more eights occurring than expected (i.e., 13.4\%). Thus, unlike prior research (e.g., Glaum et al., 2004; Aharony et al., 1993) suggesting that earnings management is more prevalent among highly leveraged firms, our results indicate that highly leveraged firms do not appear to engage in earnings manipulation geared toward effecting cognitive reference points in EPS. A specific reason the low-leverage group reports a higher than expected frequency of eights in the right EPS digit is not known.

The final characteristic examined is operating performance, which is measured for a firm as the return on assets (ROA), calculated as net income divided by total assets. The median ROA for the 749 positive earnings firms is $6.00 \%$, and this is used as the cutoff point in segregating this group into high and low operating performance subgroups. The 375 firms with ROAs exceeding $6.00 \%$ comprise the high performing subgroup, while the 374 companies with ROAs below $6.00 \%$ make up the low performing subgroup. Table 4 reports the digital counts and frequencies for the right EPS position for these two subgroups.

Table 4

EPS Digital Frequencies for High and Low ROA Firms

\begin{tabular}{|c|c|c|c|c|c|c|c|c|c|c|}
\hline & \multicolumn{10}{|c|}{ Right EPS Digit } \\
\hline & $\mathbf{1}$ & 2 & 3 & 4 & 5 & 6 & 7 & 8 & 9 & $\mathbf{0}$ \\
\hline \multicolumn{11}{|l|}{ High ROA Firms $(n=375)$ : } \\
\hline Observed count $(n)$ & 34 & 26 & 38 & 30 & 42 & 46 & 37 & 49 & 41 & 32 \\
\hline Observed frequency (\%) & 9.1 & 6.9 & 10.1 & 8.0 & 11.2 & 12.3 & 9.9 & 13.1 & 10.9 & 8.5 \\
\hline Expected frequency (\%) & 10.0 & 10.0 & 10.0 & 10.0 & 10.0 & 10.0 & 10.0 & 10.0 & 10.0 & 10.0 \\
\hline$Z$ value & -.602 & -1.980 & .086 & -1.291 & .775 & 1.463 & -.086 & 1.980 & .602 & -.943 \\
\hline$P$ level & .547 & .048 & .931 & .197 & .439 & .143 & .931 & .048 & .547 & .344 \\
\hline
\end{tabular}

Low ROA Firms (n=374):

\begin{tabular}{|c|c|c|c|c|c|c|c|c|c|c|}
\hline Observed count (n) & 38 & 35 & 45 & 35 & 30 & 43 & 33 & 35 & 37 & 43 \\
\hline Observed frequency $(\%)$ & 10.2 & 9.4 & 12.0 & 9.4 & 8.0 & 11.5 & 8.8 & 9.4 & 9.9 & 11.5 \\
\hline Expected frequency $(\%)$ & 10.0 & 10.0 & 10.0 & 10.0 & 10.0 & 10.0 & 10.0 & 10.0 & 10.0 & 10.0 \\
\hline $\mathrm{Z}$ value & .103 & -.414 & 1.310 & -.414 & -1.275 & .965 & -.758 & -.414 & -.069 & .965 \\
\hline$P$ level & .918 & .679 & .190 & .679 & .202 & .334 & .448 & .679 & .945 & .334 \\
\hline
\end{tabular}

Note: $\mathrm{Z}$ values and $P$ levels are for a one-sample proportions test comparing the observed frequency of a digit to the expected frequency of $10 \%$.

Interestingly, for the low-ROA subgroup, no observed proportion for the right EPS digit differs significantly (i.e., at an alpha level of .05) from the expected frequency of $10 \%$. Thus, it appears that, for this subgroup of firms, management does not manipulate earnings to achieve a desired reference point in EPS. For the high-ROA subgroup, though, unusual digital patterns exist as high-ROA firms report fewer twos than expected (i.e., $6.9 \%$ ) in the right EPS position and more eights than expected (i.e., 13.1\%). This pattern possesses similarities to the one exhibited by the subgroup of large firms analyzed earlier. For the large firms, there are fewer ones (a low digit) than expected and more sixes (a higher digit) than anticipated. It is unlikely these similarities exist by chance, and they suggest that high-ROA firms likely manage earnings to achieve certain EPS reference points for the same (but unknown) reason(s) as the large firms.

Given the similarities in their propensities to report a lower than expected frequency of a smaller digit and a higher than expected proportion of a larger digit, it is possible that the subgroup of large firms is made up primarily of the same firms that comprise the high-ROA subgroup. However, a comparison of the median ROAs for the subgroups of large firms and small firms reveals that this is not the case. The median ROA for the large firms of 
$6.05 \%$ does not differ significantly from the median ROA for the small firms of 5.91\% (i.e., $p$-level of .176). Thus, there is little, if any, relation between firm size and operating performance.

\section{SUMMARY AND CONCLUSION}

Prior research (i.e., Thomas, 1989; Das and Zhang, 2003) indicates that managers manipulate earnings to achieve specific reference points in EPS. The current study extends the previous research, especially that of Thomas (1989), to examine possible relations between particular company characteristics (i.e., firm size, level of leverage, and operating performance) and the propensity to manage earnings to effect the reporting of cognitive reference points in EPS. In contrast to Thomas' (1989) findings, no unusual digital patterns occur in the right EPS position when the companies are segregated and analyzed simply according to their status as negative or positive earnings firms.

However, when the group of positive earnings firms is further subdivided by entity size, leverage, and operating performance, unusual digital patterns emerge in the right EPS position. As an example, when the group of positive earnings firms is subdivided by company size, the large firms report a lower (higher) than expected frequency of ones (sixes) in the right EPS position. The small firms, though, present a different digital pattern with more (fewer) zeros (sixes) than expected in the right EPS position.

The fact that the observed digital frequencies of the right EPS position do not differ significantly from the expected frequencies before segregating the firms by size, leverage, and operating performance but do so after the firms are subdivided along these lines provides strong anecdotal evidence that the propensity to manage earnings to effect EPS reference points is related to these company characteristics. The strongest association seems to be with company size, as both the subgroups of large and small firms exhibit unusual digital patterns. For leverage, only the subgroup of firms with low leverage demonstrates an unusual digital pattern, and it is for one digit only. For operating performance, only the subgroup of high performing companies reports an unusual digital pattern, and it possesses similarities with the pattern noted for the subgroup of large firms. It is virtually impossible to prove with certainty that companies manipulate earnings to achieve desired EPS results. However, in the absence of earnings management, the unusual digital patterns in EPS documented in this study should not have occurred. Their presence leaves little alternative than to conclude that earnings are managed to effect desired EPS results and that this propensity to manage earnings is related to firm size, leverage, and operating performance.

\section{SUGGESTIONS FOR FUTURE RESEARCH}

The purpose of the current study is to determine if earnings management to effect the reporting of desired EPS numbers appears to be associated with specific company characteristics. Its objective is not to ascertain why a particular EPS digit might be desirable for one subgroup of companies but not another (e.g., why do small companies possess a strong preference for zeros in the right EPS position while large firms seemingly do not). Future research could explore why these particular preferences exist.

In addition, the current study incorporates a broad cross section of companies from multiple industries to ensure that its results are generalizable. Different findings could, of course, result from analyzing industry specific samples; thus, future research might replicate this study within particular industries.

\section{REFERENCES}

1. Aharony, J., C.J. Lin, and M.P. Loeb, Initial Public Offerings, Accounting Choices, and Earnings Management, Contemporary Accounting Research, Vol. 10, No. 1, pp. 61-81, 1993.

2. Benford, F., The Law of Anomalous Numbers, Proceedings of the American Philosophical Society, Vol. 78, No. 4, pp. 551-572, 1938.

3. Brown, L.D. and H.N. Higgins, Managing Earnings Surprises in the U.S. versus 12 Other Countries, Journal of Accounting and Public Policy, Vol. 20, No. 4/5, pp. 373-398, 2001. 
4. Burgstahler, D. and I. Dichev, Earnings Management to Avoid Earnings Decreases and Losses, Journal of Accounting and Economics, Vol. 24, No. 1, pp. 99-126, 1997.

5. Carslaw, C.A.P.N., Anomolies in Income Numbers: Evidence of Goal Oriented Behavior, The Accounting Review, Vol. 63, No. 2, pp. 321-327, 1988.

6. Das, S. and H. Zhang, Rounding-up in Reported EPS, Behavioral Thresholds, and Earnings Management, Journal of Accounting and Economics, Vol. 35, No. 1, pp. 31-50, 2003.

7. Degeorge, F., J. Patel, and R. Zeckhauser, Earnings Management to Exceed Thresholds, Journal of Business, Vol. 72, No. 1, pp. 1-33, 1999.

8. Glaum, M., K. Lichtblau, and J. Lindemann, The Extent of Earnings Management in the U.S. and Germany, Journal of International Accounting Research, Vol. 3, No. 2, pp. 45-77, 2004.

9. Guidry, F., A.J. Leone, and S. Rock, Earnings-based Plans and Earnings Management by Business-unit Managers, Journal of Accounting and Economics, Vol. 26, Nos. 1-3, pp. 113-142, 1999.

10. Healy, P.M., The Effect of Bonus Schemes on the Selection of Accounting Principles, Journal of Accounting and Economics, Vol. 7, Nos. 1-3, pp. 85-107, 1985.

11. Jackson, S. and M. Pitman, Auditors and Earnings Management, The CPA Journal, Vol. 71, No. 7, pp. 3944, 2001.

12. Jordan, C.E. and S.J. Clark, Evidence on the Level of Corporate America's Participation in the Earnings Game, The National Accounting Journal, Vol. 5, No. 1, pp. 61-70, 2003.

13. Manzon Jr., G.B., "Earnings Management of Firms Subject to the Alternative Minimum Tax," Journal of American Taxation Association, Vol. 14, No. 2, pp. 88-111, 1992.

14. Niskanen, J. and M. Keloharju, Earnings Cosmetics in a Tax-driven Accounting Environment: Evidence from Finnish Public Firms, The European Accounting Review, Vol. 9, No. 3, pp. 443-452, 2000.

15. Payne, J.L. and S.W.G. Robb, Earnings Management: The Effect of Ex Ante Earnings Expectations, Journal of Accounting, Auditing and Finance, Vol. 15, No. 4, pp. 371-392, 2000.

16. Peek, E., The Use of Discretionary Provisions in Earnings Management: Evidence from the Netherlands, Journal of International Accounting Research, Vol. 3, No. 2, pp. 27-43, 2004.

17. Pinkham, R.S., On the Distribution of First Significant Digits, Annals of Mathematical Statistics, Vol. 32 , pp. 1223-1230, 1961.

18. Porcano, T.M., An Analysis of Capital Gains Tax-induced Earnings Management, International Advances in Economic Research, Vol. 3, No. 4, pp. 395-408, 1997.

19. Sweeney, A.P., Debt-covenant Violations and Managers' Accounting Responses, Journal of Accounting and Economics, Vol. 17, No. 3, pp. 281-308, 1994.

20. Thomas, J.K., Unusual Patterns in Reported Earnings, The Accounting Review, Vol. 64, No. 4, pp. 773-787, 1989.

21. Van Caneghem, T., Earnings Management Induced by Cognitive Reference Points, British Accounting Review, Vol. 34, No. 2, pp. 167-178, 2002.

22. Van Caneghem, T., The Impact of Audit Quality on Earnings Rounding-up Behavior: Some U.K. Evidence, European Accounting Review, Vol. 13, No. 4, pp. 771-786, 2004.

23. Visvanathan, G. Deferred Tax Valuation Allowances and Earnings Management, Journal of Financial Statement Analysis, Vol. 3, No. 4, pp. 6-15, 1998.

24. Watts, R.L. and J.L Zimmerman, Towards a Positive Theory of the Determination of Accounting Standards, The Accounting Review, Vol. 53, No. 1, pp. 112-134, 1986.

25. Yoon, S. and G.A. Miller, Cash from Operations and Earnings Management in Korea, International Journal of Accounting, Vol. 37, No. 4, pp. 395-412, 2002. 